\title{
Properties of amorphous carbon microspheres synthesised by palm oil-CVD method
}

\begin{abstract}
Amorphous carbon microspheres were synthesized using a dual-furnace chemical vapour deposition method at $800-1000^{\circ} \mathrm{C}$. Palm oil-based cooking oil (PO) and zinc nitrate solution was used as a carbon source and catalyst precursor, respectively with PO to zinc nitrate ratio of 30:20 (v/v) and a silicon wafer as the sample target. Regular microsphere shape of the amorphous carbons was obtained and a uniform microsphere structure improved as the carbonization temperature increased from 800 to $1000^{\circ} \mathrm{C}$. At $800^{\circ} \mathrm{C}$, no regular microspheres were formed but more uniform structure is observed at $900^{\circ} \mathrm{C}$. Generally the microspheres size is uniform when the heating temperature was increased to $1000^{\circ} \mathrm{C}$, but the presence of mixed sizes can still be observed. X-ray diffraction patterns show the presence of oxide of carbon, $\mathrm{ZnO}$ phase together with $\mathrm{Zn}$ oxalate phase. Raman spectra show two broad peaks characteristic to amorphous carbon at 1344 and $1582 \mathrm{~cm}-1$ for the $\mathrm{D}$ and $\mathrm{G}$ bands, respectively. These bands become more prominent as the preparation temperature increased from 800 to $1000^{\circ} \mathrm{C}$. This is in agreement with the formation of amorphous carbon microspheres as shown by the FESEM study and other Zn-based phases as a result of the oxidation process of the palm oil as the carbon source and the zinc nitrate as the catalyst precursor, respectively.
\end{abstract}

Keyword: Amorphous carbon; Chemical vapor deposition (CVD); Microsphere; Palm oil; Zinc oxide 